\title{
Effect of a Walking Program on Functional Fitness Measures in Older Adults
}

Raya, H., Sanders J., Cover, T., Farabaugh, J., Horowitz, M., Bourassa, D., Forlenza, ST., Meyer, B., Paulson, S. Shippensburg University, Shippensburg, PA

Increasing physical activity for an elderly population can have a significant effect on functional fitness and activities of daily living by increasing muscular strength, endurance, and gait speed. PURPOSE: To identify functional fitness changes on an elderly population through a 6-month walking intervention program. METHODS: Twenty one healthy, older individuals were recruited from a Senior Center (age: $72.4 \pm 6.1$ yrs; height: $158.9 \pm 6.6 \mathrm{~cm}$; weight: $81.1 \pm 12.7 \mathrm{~kg}$; BMI: $31.9 \pm 0.9)$. Subjects self-selected to participate in either a walking (WG) or control (CON) group. Subjects in the WG were given a pedometer to wear and were assigned a daily step goal of eventually reaching $\geq 10,000$ steps/day. Each month, subjects were evaluated using: six-minute walk (6min) test, a $20 \mathrm{~m}$ walk at a maximum pace (with initial $2.44 \mathrm{~m}$ and middle $10 \mathrm{~m}$ components), $30 \mathrm{~s}$ chair stand (CS) task that measured the number of CS, and lastly a get-up-and-go (GUAG) task that measured the time to walk $2.44 \mathrm{~m}$ after standing from a seated position and returning to a seated position. A two-way ANOVA with repeated measures was used to make group and time (baseline vs. month 3) comparisons. RESULTS: Compared to baseline, many of the functional fitness measures improved, after 3 months' of walking intervention.

\begin{tabular}{|c|c|c|c|c|c|c|}
\hline & \multicolumn{3}{|c|}{ Walking Group } & \multicolumn{3}{c|}{ Control Group } \\
\cline { 2 - 7 } & Baseline & Month 3 & $\begin{array}{c}\% \\
\text { change }\end{array}$ & Baseline & Month 3 & $\begin{array}{c}\% \\
\text { change }\end{array}$ \\
\hline $6 \mathrm{~min}(\mathrm{~m})$ & $351.5 \pm 46.8$ & $398.1 \pm 70.4^{*}$ & 13.3 & $312.7 \pm 52.0$ & $360.8 \pm 42.7^{*}$ & 15.4 \\
\hline $\begin{array}{c}2.44 \mathrm{~m} \mathrm{Max} \\
(\mathrm{W})\end{array}$ & $987.9 \pm 186.4$ & $1126.0 \pm 248.1^{*}$ & 14.0 & $877.6 \pm 239.2$ & $939.8 \pm 217.5$ & 7.1 \\
\hline $\begin{array}{c}2.44 \mathrm{~m} \mathrm{GS} \\
\left(\mathrm{m} \cdot \mathrm{s}^{-1}\right)\end{array}$ & $1.2 \pm 0.2$ & $1.4 \pm 0.2^{*}$ & 15.4 & $1.1 \pm 0.2$ & $1.2 \pm 0.3$ & 6.6 \\
\hline $10 \mathrm{~m} \mathrm{Max} \mathrm{(s)}$ & $6.7 \pm 1.3$ & $6.4 \pm 0.7$ & -3.3 & $7.7 \pm 1.6$ & $7.5 \pm 1.4$ & -1.6 \\
\hline CS 30 (rep) & $13.0 \pm 3.1$ & $15.2 \pm 3.9 *$ & 17.0 & $11.8 \pm 2.4$ & $13.3 \pm 1.5$ & 12.3 \\
\hline GUAG (s) & $6.9 \pm 1.2$ & $6.2 \pm 1.0$ & -9.2 & $7.9 \pm 1.7$ & $7.1 \pm 1.4$ & -9.6 \\
\hline
\end{tabular}

Note: * Significantly different from the baseline $(\mathrm{p}<0.05)$.

CONCLUSION: The preliminary findings suggest that a three-month walking intervention program for older adults can significantly improve some of their functional fitness measures, which may aid in their activities of daily living. 